\title{
Effects of Etlingera elatior extracts on lead acetate-induced testicular damage: A morphological and biochemical study
}

\author{
KHOR YEN HAW $^{1}$, SRIKUMAR CHAKRAVARTHI ${ }^{2}$, NAGARAJA HALEAGRAHARA ${ }^{3}$ and MALLIKARJUNA RAO ${ }^{4}$ \\ ${ }^{1}$ Department of Post Graduate Studies, Research Laboratory; Departments of ${ }^{2}$ Pathology, and ${ }^{3}$ Human Biology, \\ Faculty of Medicine; ${ }^{4}$ Department of Pharmacy, International Medical University, Kuala Lumpur, Malaysia
}

Received August 10, 2011; Accepted September 9, 2011

DOI: $10.3892 /$ etm.2011.355

\begin{abstract}
Lead causes damage to the whole body by inducing oxidative stress. This includes the testis, in which spermatogenesis is affected. Etlingera elatior, a consumable plant that is being extensively studied for its high anti-oxidant properties, was tested against the effect of lead acetate in experimental rats. Rats were divided into groups consisting of a control, lead acetate only, Etlingera elatior treatment only, concurrent treatment of lead acetate and Etlingera elatior, post-treatment of lead acetate followed by Etlingera elatior and preventive group of Etlingera elatior followed by lead acetate. The substances were administered for 14 days and the effects were measured by protein carbonyl content (PCC), superoxide dismutase (SOD) activity, glutathione peroxidase (GPx) activity in the testis, as well as the testosterone level in the serum. Histological changes in the testis were also observed. Results showed that Etlingera elatior induced a significant reduction in the testis PCC activity, while at the same time it significantly increased the activities of SOD and GPX in the testis, and the testosterone level in the serum. Etlingera elatior also improved the histology of the testis when compared to the lead acetate-treated group. On the whole, Etlingera elatior is effective against oxidative damage caused by lead acetate in the testis.
\end{abstract}

\section{Introduction}

Lead acetate is a chemical compound. It is a white crystalline substance with a sweetish taste. Like other lead compounds, it is very poisonous. Lead acetate is used as a mordant in textile printing and dyeing, as a drier in paints and varnishes, and in preparing other lead compounds. It is an environmental and occupational toxicant which has been known to damage vital organs and suppress cellular processes. It is hazardous when

Correspondence to: Associate Professor Srikumar Chakravarthi, Department of Pathology, Faculty of Medicine, International Medical University, 57000 Kuala Lumpur, Malaysia

E-mail: srikumar_chakravarthi@imu.edu.my

Key words: lead, Etlingera elatior, oxidative stress, spermatogenesis, testis swallowed, inhaled or absorbed through the skin (1). There is a risk of cancer depending on the level and duration of exposure (2). It causes irritation to skin, eyes and the respiratory tract. It also has effects on the gum tissue, central nervous system, kidneys, blood and reproductive system (2).

Specific population groups are disproportionately at a high risk for lead exposure, especially the lower age group, such as fetuses, infants and young children, and the working class with direct contact with lead in industries (3). Manser et al in 1990 showed elevated lead levels and provided firm evidence of the contamination of the water supply, fish and other food sources by industrial effluent in big cities (4). Due to health concerns, lead from paints and ceramic products, caulking and pipe solder has been reduced dramatically in recent years. However, water pipes in some older homes may still contain lead solder. Lead can leach out into the water and enter the human body via oral ingestion or skin contact (1).

Historically, lead is a known abortifacient and spermicidal agent in the case of high exposure (5). Studies have shown that lead exposure affects the endocrine function as well as the spermatogenesis capability of the testis (5). Landrigan in 1990 also showed that occupational exposure of lead to men decreases their fertility (6). Rodamilans et al suggested that prolonged lead exposure initially produces a direct testicular toxicity followed by hypothalamic or pituitary disturbances at long exposures (7). Saxena et al concluded that lead exposure during the growing period when spermatogenesis is proceeding may result in reproductive impairment during adulthood (8).

Etlingera elatior (torch ginger) is a coarse herb widely distributed in Malaysia and Indonesia. In Malaysia, it is called kantan. Local communities ingest it by chopping the flower and adding them into laksa (various curries or soups made with rice noodles). Extracts from Etlingera species are proven to have high anti-oxidant and anti-bacterial activity (9). A study by Mohamad et al reported that 1,7-bis(4-hydroxyphenyl)-2,4,6-heptatrienone and 16-hydroxylabda-8(17),11,13-trien-15,16-olide are the two important bioactive compounds from Etlingera elatior, which are believed to have anti-oxidant properties (10). However, there are no reports available on the use of this extract in reducing lead acetate-induced testicular toxicity.

A previous study confirmed that Etlingera elatior extract successfully protects the bone marrow against lead toxicity (11). In the present study, we examined the effects of lead 
Table I. Grouping criteria for the rats based on dosage.

\begin{tabular}{llll}
\hline Group & \multicolumn{1}{c}{ Substance } & Dose & Duration \\
\hline 1 & Ultra-pure filter water (control) & - & 14 days \\
2 & Lead acetate & $500 \mathrm{ppm}$ & 14 days \\
3 & Etlingera elatior extract & $100 \mathrm{mg} / \mathrm{kg}$ body weight/day & 14 days \\
4 & Lead acetate + Etlingera elatior extract & $500 \mathrm{ppm}+100 \mathrm{mg} / \mathrm{kg}$ body weight/day & 14 days \\
5 & Lead acetate + & $500 \mathrm{ppm}+$ & 14 days \\
& Etlingera elatior extract & $100 \mathrm{mg} / \mathrm{kg}$ body weight $/$ day & 14 days \\
6 & Etlingera elatior extract + & $100 \mathrm{mg} / \mathrm{kg}$ body weight/day + & 14 days+ \\
& Lead acetate & $50 \mathrm{ppm}$ & 14 days \\
\hline
\end{tabular}

acetate toxicity on the spermatogenesis capabilities and functional damage in rat testis and the protective effect of Etlingera elatior extract on lead acetate-induced damage in rat testis.

\section{Materials and methods}

Etlingera elatior $(4 \mathrm{~kg})$ powder was extracted using a soxhlet extractor, concentrated using a rotary evaporator (Buchi, $\mathrm{R}-200, \mathrm{~S} / \mathrm{N}$ 10328562, Germany) and then freeze-dried using a freeze dryer (Freezone 4.5, Labconco, S/N 040622016S, USA) for 2 days.

All experimental procedures were in accordance with the ethical guidelines for animal experimentation, and the study protocol was approved by the Institute Research and Ethics Committee.

A total of 36 male adult Sprague-Dawley rats were purchased from UKM Animal Holdings Facility (University Kebangsaan Malaysia). They were 2 months old, with their body weight ranging from 230 to $270 \mathrm{~g}$.

Experimental design. The rats obtained were divided into six groups (Table I). Lead acetate was administered via drinking water and was recorded as per drinking water. Etlingera elatior extract was diluted with ultra-pure water to the described concentration, and forced-fed via feeding tube daily between 4 and $6 \mathrm{pm}$. At the end of the treatment period, the rats were sacrificed. Serum was collected, the testes were excised and one was preserved in $10 \%$ neutral buffered formalin. The other testis was cut and homogenized in $5 \mathrm{ml}$ PBS using a homogenizer, and the supernatant was collected and stored at $-80^{\circ} \mathrm{C}$.

The serum collected was used for the testosterone assay, while the homogenized testis was used for superoxide dismutase (SOD), glutathione peroxidase (GPx) and protein carbonyl content (PCC) ELISA kits. Both the serum sample and the homogenized testis were sent to the National Toxicological Centre in University Sains Malaysia (USM) for lead analysis.

For histopathological analysis, the testis maintained in the formalin solution was cut into half and then soaked in formalin for 1 week. The tissue was then processed and cut into 5- $\mu \mathrm{m}$ sections using a microtome. The tissue that was made into slides was stained with H\&E and observed under a microscope.

Statistical analysis. All analytical data were expressed as the means with standard deviation, with a $95 \%$ confidence interval. The level of significance $\alpha$ was set at 0.05 . p-value obtained from statistical tests was compared against $\alpha$ for significance. Data regarding the area of the seminiferous tubules, as well as the total cell count, were analyzed using Kolmogorov-Smirnov test and histograms to confirm a normal distribution. Comparison of data between various groups for the area of seminiferous tubules and total cell count was carried out using one-way ANOVA, with the post hoc test as Bonferroni test.

For the data of biochemical tests, non-parametric tests were used for statistical analysis. The level of significance was determined through the p-value which was set at 0.05 . Global comparison was carried out using the Kruskal-Wallis non-parametric test, while pair-wise comparison between individual groups was carried out using the Mann-Whitney U test.

\section{Results}

Blood lead level (BLL). The lead acetate alone group showed a significant increase in the BLL in comparison to the control $(\mathrm{p}<0.05)$. The BLL in the Etlingera elatior alone group was comparable to the control, and it was significantly lower than that of the lead acetate alone group $(\mathrm{p}<0.05)$. The lead acetate + Etlingera elatior (concurrent treatment), lead acetate + Etlingera elatior (post-treatment) and Etlingera elatior + lead acetate groups all had a BLL significantly higher when compared to that of the control ( $\mathrm{p}<0.05)$, due to administration of lead in these groups. However, the BLL of these three groups was also significantly lower than that in the lead acetate alone group ( $\mathrm{p}<0.05$ ), suggesting that Etlingera elatior successfully reduced the amount of lead in the blood circulation. Comparing among the three groups, the post-treatment group had the most significant reduction compared to the other two.

Lead level in the testis. Using pair-wise comparison, the lead acetate alone group had a testis lead level significantly higher than that of the control $(\mathrm{p}<0.05)$, suggesting that lead does accumulate in the testis. The Etlingera elatior alone group showed a testis lead level comparable to that of the control, and was significantly lower than the level in the lead acetate alone group $(\mathrm{p}<0.05)$. Similar to the BLL result, the testis lead level in the lead acetate + Etlingera elatior (concurrent treatment), lead acetate + Etlingera elatior (post-treatment) and Etlingera elatior + lead acetate was significantly higher 
Table II. Mean values of the size and total number of cells in the seminiferous tubules.

\begin{tabular}{lcc}
\hline Groups & Size $\left(\mu \mathrm{m}^{2}\right)$ & Total cells \\
\hline Group 1 - Control & $40,714.46$ & 348.08 \\
Group 2 - Lead acetate only & $37,422.37$ & 330.70 \\
Group 3 - Etlingera elatior extract only & $58,246.89$ & 338.44 \\
Group 4 - Concurrent treatment (lead acetate + Etlingera elatior extract) & $53,964.84$ & 342.64 \\
Group 5 - Post-treatment (lead acetate followed by Etlingera elatior extract) & $57,936.95$ & 396.16 \\
Group 6 - Etlingera elatior extract followed by lead acetate & $61,306.35$ & 325.72
\end{tabular}

compared to that of the control $(\mathrm{p}<0.05)$. It was also significantly lower when compared to the lead acetate alone group $(\mathrm{p}<0.05)$, suggesting that Etlingera elatior successfully reduced the amount of lead in the testis.

Testosterone. The serum level of testosterone in the lead acetate alone group was significantly lower than that in the control $(\mathrm{p}<0.05)$, showing that lead administration indeed affected testosterone production. The serum level of testosterone in the Etlingera elatior alone group and the lead acetate + Etlingera elatior group (concurrent treatment), when compared to the lead acetate alone group, were both significantly higher $(\mathrm{p}<0.05)$, but they were of similar level to the control. The lead acetate followed by Etlingera elatior (post-treatment) group also had a serum level of testosterone significantly higher than the lead acetate alone group $(\mathrm{p}<0.05)$, and it showed a slight increase when compared to the control $(\mathrm{p}<0.05)$, suggesting a reversal of damage by Etlingera elatior. In the last group, Etlingera elatior followed by lead acetate, the serum testosterone level was slightly higher when compared to the lead acetate alone group, and was significantly lower compared to the control $(\mathrm{p}<0.05)$.

Superoxide dismutase. The level of SOD in the lead acetate alone group was significantly lower than that in the control $(\mathrm{p}<0.05)$, showing that lead acetate reduced the production of SOD. In the Etlingera elatior alone group, the level of SOD was the highest among all groups. It was significantly higher than both the control $(\mathrm{p}<0.05)$ and lead acetate alone group $(\mathrm{p}<0.05)$, suggesting that the production of SOD was boosted by Etlingera elatior. The level of SOD in the lead acetate + Etlingera elatior (concurrent treatment) group was significantly higher than that in the lead acetate alone group $(\mathrm{p}<0.05)$, and was of comparable level to the control. The post-treatment group (lead acetate followed by Etlingera elatior) had the second highest level of SOD. It was also significantly higher than both the control $(\mathrm{p}<0.05)$ and the lead acetate alone group $(\mathrm{p}<0.05)$, suggesting a reversal of damage in terms of SOD. The Etlingera elatior followed by lead acetate group had a SOD level slightly lower than that of the control, but was significantly higher compared to the lead acetate alone group $(\mathrm{p}<0.05)$.

Glutathione peroxidase. Using pair-wise comparison, the lead acetate alone group had a significantly lower level of GPx compared to the control $(\mathrm{p}<0.05)$, proving that lead acetate reduced GPx production. GPx in the Etlingera elatior alone group was significantly higher than in the lead acetate alone group $(\mathrm{p}<0.05)$, but also significantly lower than the control $(\mathrm{p}<0.05)$. In the lead acetate + Etlingera elatior (concurrent treatment) group, the GPx level was almost similar to the Etlingera elatior alone group. It was significantly higher than the lead acetate alone group $(\mathrm{p}<0.05)$, but also significantly lower than the control $(\mathrm{p}<0.05)$. In the lead acetate followed by Etlingera elatior (post-treatment) group, the GPx level was significantly higher when compared to the lead acetate alone group $(\mathrm{p}<0.05)$. It was lower than the control, but not significantly. The last group, Etlingera elatior + lead acetate, had a GPx level significantly higher compared to the lead acetate alone group $(\mathrm{p}<0.05)$, but also significantly lower when compared to the control $(\mathrm{p}<0.05)$.

Protein carbonyl content. Using pair-wise comparison, the lead acetate alone group had a significantly higher level of PC than that of the control $(\mathrm{p}<0.05)$, showing that the testicular tissue was greatly damaged by lead acetate. In the Etlingera elatior alone group, the PCC was of comparable level to the control group. When compared to the lead acetate alone group, PC in the Etlingera elatior alone group was significantly lower $(\mathrm{p}<0.05)$. PC for the lead acetate + Etlingera elatior (concurrent treatment) group was significantly higher compared to that of the control $(\mathrm{p}<0.05)$, but also significantly lower than the lead acetate alone group $(\mathrm{p}<0.05)$. The lead acetate followed by Etlingera elatior (post-treatment) group and the Etlingera elatior + lead acetate group were both also significantly higher than the control $(\mathrm{p}<0.05)$, but significantly lower compared to the lead acetate alone group $(\mathrm{p}<0.05)$, suggesting a reversal of damage.

Histopathological analysis (Table II). In the control group, seminiferous tubules showed normal architecture with adequate cellularity. All cells of spermatogenic lineage were present. The basement membrane appeared normal. There was no thickening of the basement membrane. Tubules appeared healthy and no areas of fibrosis were found. Healthy quantities of Sertoli and Leydig cells were present.

By contrast, the lead acetate alone group showed shrunken seminiferous tubules and reduced cellularity. There was more reduction in matured forms when compared to immature forms, suggesting a maturation arrest. There was thickening of the basement membrane and areas of fibrosis involving both the basement membrane and the interstitium. Patches of interstitial oedema were also present. Few tubules showed inflammatory activities with residual macrophages. The blood vessels were also noted to be dilated and congested. All these 
suggested that the testis was heavily damaged by the administration of lead acetate.

The Etlingera elatior group showed healthy testicular tissue similar to the control, with a slight increase in the interstitial tissue. The concurrent treatment and post-treatment groups showed mild thickening of the basement membrane noted in certain seminiferous tubules, but otherwise appeared generally healthy. This, when compared to the lead acetate group, indicates that administration of Etlingera elatior successfully reversed the damage caused by lead acetate in the testicular tissue. The Etlingera elatior followed by the lead acetate group appeared to be less healthy, with mild atrophy and a paucity of cells inside the tubules suggesting growth arrest. Moderate thickening of the basement membrane was also noted with some interstitial oedema and focal areas of fibrosis. This shows that Etlingera elatior administered as a treatment option may produce a beneficial outcome.

The lead acetate group showed a reduction in total cells when compared to the control. The Etlingera elatior group showed an increase in cellularity, which was nearly similar to the control and marginally lower. The post-treatment group showed a good increase in cellularity, which was higher compared to the control. The concurrent treatment group showed moderate cellularity, which was almost similar to the control. The Etlingera elatior followed by the lead acetate group showed a reduction in cellularity and was the lowest of all groups.

\section{Discussion}

Observing the BLL results, the administration of lead in drinking water induced a high BLL in the lead acetate alone group, confirming that lead is highly absorbed into the body through the gastrointestinal tract. The BLL of the lead acetate alone group was much higher than the safe level of $10 \mu \mathrm{g} / \mathrm{dl}$ (11). From the result of the obtained levels of lead in the testis, it was observed that a high concentration of lead was deposited in the testis in the lead acetate alone group, which was approximately half the concentration of lead in the blood circulation. This proves that the testis is a site at risk from lead intoxication. It was observed that administration of Etlingera elatior either concurrently with lead acetate, post-administration of lead acetate, or prior to administration of lead acetate, does have an effect in lowering the level of lead in both blood and testis. However, the BLL in all three groups did not drop back to the acceptable safe level of $10 \mu \mathrm{g} / \mathrm{dl}$, although this could probably be achieved by prolonging the treatment period.

Comparing among the three groups, the post-treatment group had the most significant reduction in lead level in the blood and testis, suggesting that Etlingera elatior treatment is most effective in removing lead in the body post-exposure to lead. While administering it concurrently, the active contents of Etlingera elatior may be inhibited or used up. Administered before lead acetate, Etlingera elatior may be utilized against other oxidative challenge and thus the effect against lead is reduced.

Lead is known to bring about damage in tissues by inducing oxidative stress. It creates a high content of reactive oxygen species in our body and also depletes anti-oxidant enzymes (12). This was proven once again based on the biochemical result obtained, where SOD and GPx were reduced in the lead acetate alone group, while the protein carbonyl content was increased. SOD and GPx are the two main enzymes involved in the anti-oxidant defense mechanism in our body. SOD works against superoxide anions, while GPx protects tissues and cells against lipid hydroperoxide and hydrogen peroxide (13). There are different types of SODs, depending on the metals that co-factor with the protein, including $\mathrm{Cu}, \mathrm{Zn}, \mathrm{Fe}$, $\mathrm{Mn}$ and Ni (14). Lead is believed to displace metals in the functional group of SOD. This is based on the fact that lead being itself bivalently charged in ionic form is able to displace bivalent ions, such as $\mathrm{Zn}^{2+}, \mathrm{Cu}^{2+}$ and $\mathrm{Fe}^{2+}$ (19), rendering the resultant enzyme useless in catalyzing the redox reaction. The same principle holds true for the reduction in GPx level. Lead displaces the selenocysteine group from the active site of GPx, which is responsible for its catalytic functions $(15,16)$. PC is formed when amino acid residues on protein molecules, such as lysine, arginine, proline and histidine, are oxidized (17). The oxidizing agent for PC is ROS. Hence, in the result obtained, an increase in PC is directly attributed to an increased ROS level induced by lead acetate.

In another study by Sharma et al (18), rats were administered lead nitrate for 7 days. Biochemical tests afterwards showed a significant increase in PC and a significant decrease in SOD level. There was also a significant increase in tissue lead level. The results of this study are in accordance with our study, and our results are also in accordance with other studies, in which a significantly higher level of lead was detected by chemiluminescence in groups treated with lead for 6 months. The elevated lead level was found in blood, testicular tissue and epididymis (19-21).

In our study, Etlingera elatior was also used as a treatment, both concurrently to lead acetate administration and also post-exposure to lead acetate. The SOD level was significantly increased when compared to both the control and lead acetate alone group. This suggests that Etlingera elatior enhances the production of SOD. In the concurrent treatment group, SOD was brought back to the control level, while in the posttreatment group, SOD level was increased almost to the level of the Etlingera elatior alone group. In the Etlingera elatior followed by the lead acetate group, however, the SOD level was increased, but still slightly lower compared to the control. This suggests that Etlingera elatior is most effective when administered post-exposure to lead, and that the GPx has a very similar result as SOD. In the concurrent treatment group, GPx was increased to a significantly higher level compared to the lead acetate alone, although it was still significantly lower than the control. This result was similar for the Etlingera elatior followed by the lead acetate group. Again, the post-treatment group appeared to be the most effective group in terms of the efficacy of Etlingera elatior against lead toxicity, with the GPx level reverted back to almost the level of the control. Comparing the $\mathrm{PC}$, which indicates tissue or cell injury from oxidative stress, all of the treatment and prevention groups showed a significant decrease compared to the lead acetate alone group. Among the three groups, the post-treatment group again confirmed that Etlingera elatior is best administered post-exposure to lead. The results obtained confirm that posttreatment is the most optimal option compared to concurrent treatment, with administration of Etlingera elatior prior to lead acetate administration conferring a lesser protective effect. 

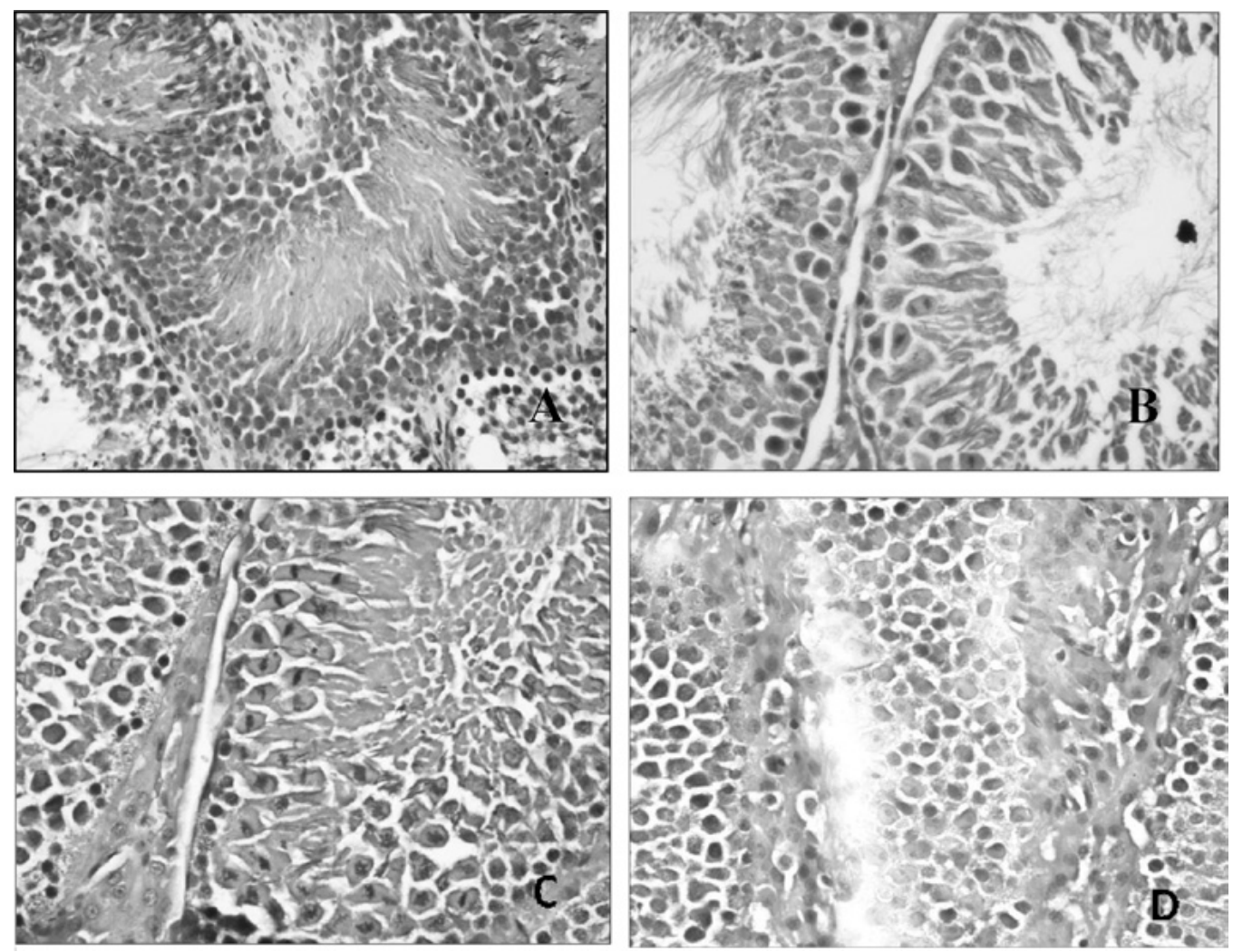

Figure 1. Photomicrograph of testicular tissue from (A) the lead acetate group showing thickening of basement membrane with fibrosis affecting the lumen and an area of central necrosis (magnification, x200; H\&E); (B) the Etlingera elatior group showing healthy testicular tissue with abundant mitotic spermatogenic cells (magnification, $\mathrm{x} 400 ; \mathrm{H} \& \mathrm{E}$ ); (C) the concurrent treatment group showing healthy testicular tissue with abundant mitotic spermatogenic cells (magnification, $\mathrm{x} 400 ; \mathrm{H} \& \mathrm{E}$ ); (D) the post-treatment group showing mild thickening of basement membrane and increased interstitial tissue (magnification, $\mathrm{x} 400 ; \mathrm{H} \& \mathrm{E}$ ).

The serum testosterone level was significantly reduced in the lead acetate alone group. In the concurrent treatment group, Etlingera elatior successfully brought back the testosterone level to the control level. In the Etlingera elatior followed by the lead acetate group, the testosterone level increased, but still remained significantly lower than the control. The post-treatment group exhibited the highest level of testosterone, even slightly higher than the control, suggesting that Etlingera elatior is also most effective when administered post-exposure to lead in recovering the testosterone level.

Histopathological alterations noted under the microscope included shrunken seminiferous tubules, decreased cellularity with reduction in matured forms when compared to immature forms, suggesting a maturation arrest, thickening of basement membrane, fibrosis affecting both the basement membrane and the interstitium (Fig. 1). Our findings are consistent with other studies $(22,23)$, in which many changes were observed after lead administration for 30 days, including shrunken seminiferous tubules with a wavy outline, thickened basement membrane with hyalinization, maturation arrest with abnormal ratio of spermatogenic cells and also abnormalities in interstitial Leydig cells.

In the Etlingera elatior alone group, normal spermatogenesis was noted to be actively ongoing (Fig. 1B) with abundant mature spermatozoa formed. However, it was also noted that the interstitial tissue was increased with certain areas of interstitial oedema, suggesting that Etlingera elatior promotes the growth of interstitial tissue. In the concurrent treatment group, the histology of the testicular tissue was similar to the Etlingera elatior alone group, with normal spermatogenesis (Fig. 1C) noted and abundant mature spermatozoa formed. There was also an increased interstitial tissue observed, but in addition to that, congestion of blood vessels was also noted and a moderate thickening of the basement membrane. This suggests that Etlingera elatior protects the testicular tissue with only minor changes occurring. In the post-treatment group, normal architecture of seminiferous tubules was noted, with actively ongoing spermatogenesis. However, it was observed that there was mild thickening of the basement membrane (Fig. 1D), increased interstitial tissue with abundant Leydig cells, congestion of blood vessels and the presence of few macrophages in some of the seminiferous tubules. The testicular tissue in this group, although showing all the above-mentioned minor changes, generally appeared healthy, showing that the damage that lead had caused was repaired by the Etlingera elatior post-exposure to lead acetate. The presence of macrophages again was deduced to aid in removing excessive lead present in the testicular tissue. The Etlingera elatior followed by the lead acetate group, on the other hand, appeared to sustain more damage than the two treatment groups. Moderate thickening of the basement membrane was noted with some areas of interstitial oedema (Fig. 1D), and a paucity of cells also suggest that there was a maturation arrest of spermatogenic cells. There was also some 
congestion of blood vessels noted. Collectively, the tissues appeared to be mild to moderately atrophic, confirming with the biochemical tests that Etlingera elatior administered prior to lead acetate administration is not as beneficial as a treatment. Again, comparison to other studies was not possible due to the lack of studies on the effect of Etlingera elatior against lead toxicity in the testis. However, our result is still supported by the fact that Etlingera elatior contains a high level of anti-oxidant activity (24), bringing about the promising result obtained.

In conclusion, Etlingera elatior is indeed a beneficial treatment option against lead-induced oxidative stress in testicular tissue. Among the treatment method options, administration of Etlingera elatior post-exposure to lead yields the most beneficial result. Further investigations are warranted as Etlingera elatior can be a potential complimentary agent in treating chronic lead intoxication.

\section{Acknowledgements}

This study was done under the research grant no. BMS-I-02/ 2010(06) provided by the International Medical University, Malaysia

\section{References}

1. Fu $\mathrm{H}$ and Boffetta P: Cancer and occupational exposure to inorganic lead compounds: a meta-analysis of published data. Occup Environ Med 52: 73-81, 1995.

2. Damstra T: Toxicological properties of lead. Environ Health Perspect 19: 297-307, 1977.

3. Rader JI, Peeler JT and Mahaffey KR: Comparative toxicity and tissue distribution of lead acetate in weanling and adult rats. Environ Health Perspect 42: 187-195, 1981.

4. Manser WW, Lalani R, Haider S and Khan MA: Trace element studies on Karachi populations. Part V: Blood lead levels in normal healthy adults and grammar school children. J Pak Med Assoc 40: 150-154, 1990.

5. Gorbel F, Boujelbene M, Makni-Ayadi F, Guermazi F, Croute F, Soleilhavoup JP and el Feki A: Cytotoxic effects of lead on the endocrine and exocrine sexual function of pubescent male and female rats. Demonstration of apoptotic activity. C R Biol 325: 927-940, 2002.

6. Landrigan PJ: Current issues in the epidemiology and toxicology of occupational exposure to lead. Environ Health Perspect 89: 61-66, 1990.

7. Rodamilans M, Osaba MJ, To-Figueras J, Rivera Fillat F, Marques JM, Perez P and Corbella J: Lead toxicity on endocrine testicular function in an occupationally exposed population. Hum Toxicol 7: 125-128, 1988
8. Saxena DK, Srivastava RS, Lal B and Chandra SV: The effect of lead exposure on the testis of growing rats. Exp Pathol 31: 249-252, 1987.

9. Chan EWC, Lim YY and Omar M: Antioxidant and antibacterial activity of leaves of Etlingera species (Zingiberaceae) in Peninsular Malaysia. Food Chem 104: 1586-1593, 2007.

10. Mohamad H, Lajis NH, Abas F, Ali AM, Sukari MA, Kikuzaki H and Nakatani N: Antioxidant constituents of Etlingera elatior. J Nat Prod 68: 285-288, 2005.

11. Wu A: Tietz Clinical Guide to Laboratory Tests. 4th edition. Saunders Elsevier, St. Louis, MO, pp658-659, 2006.

12. Marchlewicz M,WiszniewskaB,GonetB,Baranowska-BasiockaI, Safranow K, Kolasa A, Glabowski W, Kurzawa R, Jakubowska K and Rac ME: Increased lipid peroxidation and ascorbic acid utilization in testis and epididymis of rats chronically exposed to lead. Biometals 20: 13-19, 2007.

13. Ran Q, Liang H, Ikeno Y, Qi W, Prolla TA, Roberts LJ II, Wolf N, van Remmen $\mathrm{H}$ and Richardson A: Reduction in glutathione peroxidase 4 increases life span through increased sensitivity to apoptosis. J Gerontol A Biol Sci Med Sci 62: 932-942, 2007.

14. Marklund S: Distribution of $\mathrm{Cu} \mathrm{Zn}$ superoxide dismutase and $\mathrm{Mn}$ superoxide dismutase in human tissues and extracellular fluids. Acta Physiol Scand 492: S19-S23, 1980.

15. Ursini F, Maiorino M and Gregolin C: The selenoenzyme phospholipid hydroperoxide glutathione peroxidase. Biochim Biophys Acta 839: 62-70, 1985.

16. Forstrom JW, Zakowski JJ and Tappel AL: Identification of the catalytic site of rat liver glutathione peroxidase as selenocysteine. Biochemistry 17: 2639-2644, 1978.

17. Stadtman ER and Oliver CN: Metal-catalyzed oxidation of proteins: physiological consequences. J Biol Chem 266: 2005-2008, 1991.

18. Sharma V, Kansal L and Sharma A: Prophylactic efficacy of Coriandrumsativum (Coriander) on testis of lead-exposed mice. Biol Trace Elem Res 136: 337-354, 2010.

19. Marchlewicz M, Michalska T and Wiszniewska B: Detection of lead-induced oxidative stress in the rat epididymis by chemiluminescence. Chemosphere 57: 1553-1562, 2004.

20. Haleagrahara N, Jackie T, Chakravarthi S, Rao M and Pasupathi T: Protective effects of Etlingera elatior extract on lead acetate-induced changes in oxidative biomarkers in bone marrow of rats. Food Chem Toxicol 48: 2688-2694, 2010.

21. Haleagrahara N, Jackie T, Chakravarthi S, Rao M and Kulur A: Protective effect of Etlingera elatior (torch ginger) extract on lead acetate - induced hepatotoxicity in rats. J Toxicol Sci 35: 663-671, 2011

22. Ahmad I, Sabir M and Yasin KF: Study of the effects of lead poisoning on the testes in albino rats. Pak J Med Res 422: 256-262, 2003.

23. Ghelberg NW and Bordas E: Lead-induced experimental lesions of the testis and their treatment. J Appl Toxicol 1: 284-286, 1981.

24. Chan EWC, Lim YY, Wong LF, Lianto FS, Wong SK, Lim KK, Joe CE and Lim TY: Antioxidant and tyrosinase inhibition properties of leaves and rhizomes of ginger species. Food Chem 109: 477-483, 2008. 